\title{
Estratégias de inovação de catching-up: as ligações de aprendizagem entre um instituto de P\&D e pequenas empresas
}

\author{
Ana Sílvia Rocha Ipiranga \\ Universidade Estadual do Ceará \\ Waleska Vasconcelos Queiroz \\ Universidade Estadual do Ceará \\ Gleildes dos Santos Lima Frota \\ Universidade Estadual do Ceará \\ Samuel Façanha Câmara \\ Universidade Estadual do Ceará \\ Priscilla Corrêa da Hora Almeida \\ Universidade Estadual do Ceará
}

\begin{abstract}
Considerando que diferentes estratégias são utilizadas pelas organizações para potencializar seu desempenho por meio da inovação, este estudo teve como objetivo identificar as ligações de aprendizagem entre um instituto de P\&D e pequenas empresas da cadeia produtiva da caprinocultura inserida no sistema de inovação local, tendo como base a seguinte questão: os institutos de P\&D podem funcionar como porteiro tecnológico (gatekeepers) provendo conhecimento novo às pequenas empresas em estudo? Para isso foi elaborado o marco teórico do estudo baseado nas discussões referentes às estratégias e aos sistemas de inovação, articulando ainda as temáticas sobre pesquisa e desenvolvimento - P\&D e os processos de aprendizagem correspondentes. A metodologia está baseada na estratégia do estudo multicaso. Os dados empíricos foram examinados segundo a abordagem qualitativa, sendo coletados através de entrevistas semiestruturadas, durante participações em reuniões e análises documentais. Nas empresas pesquisadas, observou-se que, apesar de essas manterem ligações de aprendizagem ainda incipientes com o instituto de P\&D, evidências mostraram que estas estão incidindo na ampliação da base de conhecimento das pequenas empresas. Relevou-se ainda que estas ligações de aprendizagem estejam sendo ampliadas e potencializadas através das fontes externas e abertas entre as empresas e as demais instituições do sistema e que tiveram como base estratégias de inovação do tipo catching-up.
\end{abstract}

Palavras-chave: estratégias; aprendizagem e sistemas de inovação; P\&D; pequenas empresas.

Artigo recebido em 21 dez. 2010 e aceito em 20 jun. 2011.

RAP - Rio de Janeiro 46(3):677-700, maio/jun. 2012 
Catching-up innovation strategies: learning connections between an R\&D institute and small companies

Considering that different strategies are used by the organizations to increase their performance through innovation, this study had the objective of identifying the learning connections between an R\&D institute and in goat small companies of the local innovation system, tends as base the following question: can R\&D institutes work as technological gatekeepers providing new knowledge to the companies under study? For that, the theoretical mark of the study was elaborated based on the discussions about strategies and innovation systems, also articulating the themes on research and development - R\&D and the processes of corresponding learning. The methodology is based on the strategy of multi case study. The empiric data were examined according to the qualitative approach, being collected through semi-structured interviews, during participation in meetings and documentary analysis. In the researched companies, it was observed that, those firms still maintain incipient connections with the R\&D institute. In the other hands, evidence showed that they are focusing on expanding the knowledge base of small businesses. It is also shown that these links are being expanded and potentiated learning by external and open sources between companies and other institutions of the system, which had catching-up innovation strategies as a base.

KEY WORDs: strategies; learning and innovation systems; R\&D; small companies.

\section{Introdução}

Um dos fatores decisivos da competitividade é a inovação. A inovação é frequentemente citada como crucial para o estabelecimento e a manutenção da vantagem competitiva sustentável das empresas, tendo real importância tanto para pequenas quanto para grandes organizações (Cooper, 2008; Porter, 1983).

Nesse contexto, a infraestrutura tecnológica tem despertado crescente interesse em diversos segmentos políticos e socioeconômicos, incluindo tomadores de decisão públicos e privados, agências de desenvolvimento governamentais, empreendedores e a comunidade acadêmica e de pesquisa e desenvolvimento (P\&D). Assim, a era da informação e da inovação tecnológica, aliada ao mercado competitivo, obriga as empresas a implementarem estratégias para buscarem a inovação constante em seus produtos e processos de gestão, mantendo seus posicionamentos nos setores em que atuam, e superarem o número crescente de concorrentes novos que emergem continuamente.

Considerando-se o papel fundamental da transformação tecnológica na concorrência, as organizações devem procurar avaliar quais tecnologias são mais significativas visando alavancar seu desempenho e vantagens competitivas. Nesses termos, a atuação organizacional pode ser determinada a partir de dois tipos de estratégias de inovação: liderança na fronteira tecnológica (overtaking) e/ou de seguimento tecnológico (catching-up) (Porter, 1990; Bessant, 2005; Nelson, 2007).

Por outro lado, uma das principais características das empresas dos países emergentes (latecomers) refere-se a suas deficiências de recursos ou de capacidades tecnológicas. Conforme Figueiredo (2009), as latecomers estão em geral deslocadas das fontes-chave de tecnologia 
como as universidades, laboratórios e institutos de P\&D, ou seja, a infraestrutura tecnológica que a cerca tende a ser em geral precária. Contudo, essa situação deve ser relativizada, pois as possibilidades de interação, de mobilidade e conectividade contribuem para evitar o isolamento das latecomers, sobretudo, quando estas participam de cadeias produtivas e estão inseridas nos sistemas de inovação (Figueiredo, 2009).

Releva-se, portanto, que um dos objetivos de inovação industrial é o fortalecimento da capacidade tecnológica de pequenas e médias empresas (PMEs) no sentido de atuarem na cadeia de fornecedores de grandes empresas locais e internacionais. Nesse sentido, os estudos empíricos que abordem o desenvolvimento tecnológico de PMEs em vez de tomá-las de maneira isolada deveriam examinar suas relações com as demais empresas e instituições envolvidas nas cadeias produtivas e/ou nos sistemas de inovação (Figueiredo, 2009; Schmitz, 2004).

Um sistema de inovação pode ser definido como um conjunto de instituições distintas que estabelecem ligações de forma conjunta e/ou individualmente, contribuindo para o desenvolvimento de aprendizagem e difusão de tecnologias, onde ocorre o envolvimento não somente de empresas, mas, principalmente, entre instituições de ensino, centros de P\&D e outras organizações de financiamento e governamentais (Lundvall, 1982; Nelson, 1993; Cassiolato e Lastres, 2000).

Nesse sentido, as empresas que iniciam suas atividades numa condição de recursos escassos têm de buscar conhecimento de fora a fim de construir e acumular suas próprias capacidades. Para uma empresa construir suas capacidades inovadoras, a alavancagem de recursos externos é um dos principais meios para executar a estratégia de catching-up e/ou de liderança na fronteira tecnológica (overtaking) (Bell e Pavitt, 1995; Figueiredo, 2009).

Nesse contexto, os esforços em P\&D de uma organização podem conduzi-la, portanto, à vantagem competitiva. Insumos intangíveis como informação, conhecimento, aprendizado, interações e adaptação são de suma importância para empresas que estão dispostas a alcançar essa vantagem competitiva.

No contexto dessa discussão, evidencia-se ainda que nos sistemas de inovação dos países de industrialização tardia o governo tem o papel de promotor, regulador, executor e financiador do desenvolvimento científico, da pesquisa e da capacitação tecnológica. As organizações dos sistemas de inovação participam de programas governamentais de incentivo à cooperação, nos quais a responsabilidade pela implementação recai em geral sobre a universidade, laboratórios e institutos de P\&D (Moreira et al., 2007).

De acordo com Bell (1993), os países de industrialização tardia construíram suas instalações de P\&D de uma forma bem diferente dos países industrializados. Foram raras as capacidades de $P \& D$ industrial que evoluíram a partir de uma base prévia de capacidades construídas dentro das próprias empresas. Estas foram geralmente estabelecidas em institutos centralizados, que foram financiados e operados pelo governo.

Bell (1993) complementa afirmando que não é surpresa que o problema das ligações entre os institutos de P\&D com o setor de produção tem sido uma prioridade da agenda política desde então desses países. O mesmo autor menciona ainda que existe um gap crescente entre os institutos de $\mathrm{P} \& \mathrm{D}$ e os setores produtivos. 
Nesse sentido, Nelson (2007) releva a importância no século XXI do papel das universidades, laboratórios e institutos de P\&D participantes dos sistemas de inovação, a partir da transferência, difusão e aplicação de conhecimentos, visando o desenvolvimento econômico sustentável das regiões e países. Ainda segundo Nelson (2007), para que o treinamento e a pesquisa feita nas universidades e outras instituições públicas contribuam para o desenvolvimento econômico, é necessário adensar as ligações efetivas entre essas instituições, as organizações e os setores produtivos.

Tendo em vista a mudança tecnológica em empresas participantes de sistemas de inovação, Bell (1993) coloca a necessidade da integração da P\&D com a estrutura produtiva das empresas, através do fortalecimento das ligações entre as estruturas institucionais existentes e do desenvolvimento da capacidade de assimilação e aprendizagem tecnológica por parte das empresas.

Os institutos de P\&D surgem, portanto, no ambiente dos sistemas de inovação com o papel de serem o membro articulador entre os agentes devido a sua neutralidade em sanar as deficiências estruturais, sobretudo, em termos de desenvolvimento de mecanismos de aprendizagem e de competências tecnológicas (Bell, 1993).

Nesse contexto, releva-se que os processos de aprendizagem são insumos que permitem à empresa acumular suas próprias competências tecnológicas, ampliando sua base interna de conhecimentos. Esses processos de aprendizagem tecnológica podem ocorrer através de mecanismos intraempresariais (alavancagem do conhecimento através dos mecanismos de aprendizagem externa e interna); e de mecanismos interempresariais que ocorrem por meio do estabelecimento de vínculos tecnológicos entre empresas e as demais instituições de apoio ao sistema de inovação, entre estas, os institutos de P\&D (Figueiredo, 2009).

Conforme Bell e Albu (1999), essas perspectivas anteriormente sintetizadas enfatizam a importância das "ligações internas", produzindo recursos geradores de mudança, e das "ligações externas", facilitando os recursos geradores de conhecimentos, obtidos através de organizações especializadas como os institutos de P\&D. Essas perspectivas sugerem ainda as questões relativas às instituições que fazem o papel de "porteiros tecnológicos" (gatekeepers) ou "janelas tecnológicas" (technological windowing) provendo conhecimento novo aos sistemas de inovação (Schmitz, 2004; Rabellotti, 1995; Nadvi, 1996; Bell e Albu, 1999; Maggioni e Ricci, 2002).

Para fins desse estudo destaca-se, portanto, no contexto do sistema de inovação, o papel de organizações de apoio, como os institutos de P\&D como porteiro tecnológico (gatekeepers) provendo conhecimento novo às empresas e facilitando estratégias de inovação, em termos de catching-up (movimento de alcance) e ou overtaking (movimento de ultrapassagem) da fronteira tecnológica.

Tendo como base essa discussão, considera-se como objetivo deste estudo identificar as ligações de aprendizagem entre um instituto de P\&D e pequenas empresas participantes da cadeia produtiva da caprinocultura e inserida no sistema de inovação local, tendo como base a seguinte questão: os institutos de P\&D podem funcionar como porteiro tecnológico (gatekeepers) provendo conhecimento novo às pequenas empresas do setor da caprinocultura 
em estudo? Pretende-se ainda refletir os resultados do estudo em termos de implicações para as políticas públicas relacionadas ao setor.

O critério de seleção das três empresas em estudo foi estabelecido pela acessibilidade e, sobretudo, por estas integrarem a Associação dos Criadores de Caprinos Leiteiros do Estado do Ceará (Caprileice) e participarem, através da Caprileice, do sistema de inovação local, mantendo, em consequência, ligações de aprendizagem com o Instituto de P\&D da Embrapa Caprinos e Ovinos.

Para a análise de cunho qualitativo, foi utilizada uma adaptação do modelo desenvolvido por Vedovello e Figueiredo (2006), que avalia as ligações de aprendizagem entre as empresas e as organizações de apoio ao sistema de inovação que venham a contribuir para o desenvolvimento do processo inovador em nível de empresas.

Este artigo está organizado em seções, além desta introdução. Inicialmente, é abordada a base conceitual do estudo articulando os temas das estratégias e sistemas de inovação; e ainda as discussões sobre P\&D e os processos de aprendizagem correspondentes. O contexto empírico compõe a seção que segue. No próximo tópico são relatados os procedimentos metodológicos da pesquisa e, por fim, apresentam-se os principais resultados obtidos e as considerações finais.

\section{As estratégias de inovação}

Diferentes estratégias são utilizadas pelas organizações para potencializar seu desempenho por meio da inovação. A definição de uma estratégia de inovação tem como objetivo determinar qual o papel da inovação no direcionamento estratégico, de forma que as práticas de inovação possam colaborar com a melhoria do desempenho organizacional e para o alcance dos objetivos de negócio; com isso, destaca-se a preocupação de alguns autores em definir uma tipologia para as estratégias de inovação (Cunha e Bignetti, 2006).

De acordo com Freeman (1987), as empresas podem se posicionar estrategicamente para a inovação de seis diferentes formas: ofensiva, defensiva, imitativa, dependente, tradicional e oportunista. As estratégias não são exclusivas e as empresas acabam adotando gradações ou combinações de diferentes alternativas:

v A estratégia ofensiva é adotada por uma empresa que visa a liderança, entre seus concorrentes, tanto no mercado como em tecnologia.

จ A estratégia defensiva é adotada por empresas que investem em pesquisa intensivamente e estão prontas a reagir a inovações lançadas pelos concorrentes.

v As empresas que adotam a estratégia imitativa reagem às inovações, mas se mantêm no mercado por meio de cópias com algumas modificações do projeto dos concorrentes.

v A estratégia independente diz respeito a empresas que estão institucional ou economicamente sujeitas a outras. Como exemplo, temos as multinacionais; neste caso as inovações são demandadas pelas matrizes. 
、 No caso da estratégia tradicional, esta dispensa inovações tecnológicas e se encontra em setores que não demandam mudanças.

จ Por último, a estratégia oportunista, em que a empresa explora nichos de mercado.

Porter (1990) afirma que no contexto tecnológico a estratégia configura o método para o desenvolvimento e uso da tecnologia, devendo contemplar as tecnologias relevantes em uso, as trajetórias prováveis das transformações técnico-científicas, a capacitação tecnológica disponível e a seleção de alternativas para a viabilização das tecnologias necessárias ou consideradas críticas.

Desta forma, tendo em conta o papel fundamental da transformação tecnológica na concorrência, a organização deve procurar avaliar quais tecnologias e transformações são mais significativas visando alavancar seu desempenho e vantagens competitivas.

Com isso, a atuação organizacional pode ser determinada a partir de dois tipos de estratégias de inovação: liderança na fronteira tecnológica (overtaking) e/ou seguimento tecnológico (catching-up). Essas estratégias objetivam, a partir dos processos de aprendizagem subjacentes, o desenvolvimento de inovações, impulsionando o movimento das trajetórias no sentido de alcançar (catching-up) e/ou ultrapassar (overtaking) a fronteira da produção e/ou de inovação existente (Porter, 1990).

Nessa linha de discussão, relevam-se os estudos que tiveram como base a perspectiva de catching-up ao demonstrarem como as empresas aceleraram suas trajetórias de alcance (catching-up) e de ultrapassagem (overtaking) da fronteira tecnológica, enfatizando a análise de fatores organizacionais e contextuais que incidiram na ampliação de suas bases de conhecimentos, como: as mudanças ocorridas no aparato institucional; a emergência de novos mercados e tecnologias; novas regras políticas; mudanças no modelo de gestão e arquiteturas organizacionais (Bessant, 2005; Nelson, 2007). Aliam-se a essa linha de investigação as evidências sobre os processos de catching-up nos estudos realizados nas latecomers do Sudeste asiático, ao focalizarem a atenção na construção de capacidades tecnológicas inovadoras a partir dos sucessos obtidos no mercado internacional (Amsden, 1989; Hobday, 1995, 2000; Lee e Lim, 2001).

Por outro lado, segundo Figueiredo (2009), releva-se que um dos objetivos de inovação industrial é o fortalecimento da capacidade tecnológica de pequenas e médias empresas (PMEs) no sentido de atuarem na cadeia de fornecedores de grandes empresas locais e internacionais. Desse modo, os estudos empíricos que abordem o desenvolvimento tecnológico de PMEs em vez de tomá-las de maneira isolada deveriam examinar suas relações com as demais empresas e organizações envolvidas na cadeia produtiva e/ou nos sistemas de inovação (Figueiredo, 1990).

Segundo Bell e Albu (1999), as combinações de capacidades organizadas internamente nas empresas com recursos de conhecimento externos e as ligações entre eles são descritas como "sistemas de inovação industriais", "sistemas de tecnologia" ou ainda "sistemas de conhecimento" e/ou "sistemas locais e nacionais de inovação". Essa discussão será articulada no próximo item. 


\subsection{Os sistemas de inovação}

Conforme Schumpeter (1982), a inovação é crucial no processo de desenvolvimento ao impelir os ciclos de crescimento econômicos. Contudo se registra que ao longo das últimas duas décadas as transformações no processo inovador acontecem no sentido de que ele passa a depender cada vez mais de processos interativos de natureza explicitamente social. Tais alterações ocorrem em diferentes níveis e, por conseguinte, em diferentes fases do processo inovador. Pesquisa, desenvolvimento tecnológico e difusão constituem parte de um mesmo processo.

A colaboração entre firmas e a montagem de redes de empresas têm marcado o processo inovador. Novos produtos têm sido desenvolvidos a partir da integração de diferentes tecnologias e essas são crescentemente baseadas em diferentes disciplinas científicas. Mesmo grandes empresas têm dificuldade em abordar a variedade de domínios científicos e tecnológicos necessários, o que explica a expansão de acordos colaborativos e a crescente expansão de redes de empresas visando a geração de inovações (Cassiolato e Lastres, 2000).

No que tange especificamente às políticas de inovação, Cassiolato e Lastres (2000) evidenciam o enfoque baseado nos estudos de Lundvall (1982), a partir do qual essas têm sido desenhadas, tendo como base a abordagem dos sistemas de inovação, em suas diferentes dimensões - supranacional, nacional e subnacional ou local.

O conceito de sistema de inovação foi desenvolvido paralelamente em diferentes lugares, como na Europa e nos EUA na década de 1980 (Lundvall, 2007). Freeman (1982) e Gregersen e Johnson (1996) sugerem pensar o sistema de inovação como uma organização que cria e distribui conhecimento, utilizando e agregando valor a esse conhecimento para introduzir inovações na economia, incrementando a competitividade local, nacional e internacional.

Segundo Nelson e Rosenberg (1993), o sistema de inovação envolve diversas instituições e mecanismos inter-relacionados, que dão suporte ao processo inovador e moldam os caminhos pelos quais a inovação acontece em determinada sociedade. Nesse sentido, nações são importantes para favorecer o crescimento econômico, por causa dessa interdependência entre contingências técnicas e institucionais.

Considerando-se o caso do Japão, Freeman (1987) enfatiza quatro características essenciais para o caráter sistêmico do sistema nacional da inovação. Primeiramente, o Japão revelou uma combinação adequada de intervencionismo público com os comportamentos das empresas para garantir o efeito catching-up do pós-guerra. A intervenção pública e, especialmente, o Miti japonês permitiram a mudança de foco do comportamento das empresas japonesas, incentivando os desenvolvimentos tecnológicos a longo prazo. Em segundo lugar, a organização do investimento privado em P\&D se revelou eficaz, a fim de desenvolver estratégias para garantir a rentabilidade das empresas. Terceiro: o sistema educacional (incluindo formação profissional) revelou-se de alto desempenho, favorecendo a adaptabilidade do capital humano às necessidades da indústria. Em quarto lugar, um conjunto específico de iniciativas para coordenar as principais empresas industriais contribuiu para a prevenção de comportamentos oportunistas bem como garantiu uma alocação adequada dos recursos de produção (Freeman, 1987). 
A capacidade inovadora de um país ou região decorre, portanto, das relações entre os atores econômicos, políticos e sociais. Essas relações refletem a cultura local, que é crucial em vários processos de mudança. Outra dimensão decisiva do sistema de inovação é a financeira, principalmente em países menos desenvolvidos onde as políticas devem instituir agências com essa finalidade (Lastres e Cassiolato, 2005).

Nesses termos, um sistema de inovação pode ser definido como um conjunto de instituições distintas que estabelecem ligações conjunta e individualmente, contribuindo para o desenvolvimento de aprendizagem e difusão de tecnologias, em que ocorre o envolvimento não somente de empresas, mas, principalmente, entre instituições de ensino, centros de P\&D e outras organizações de financiamento e governamentais (Lundvall, 1982; Nelson, 1993; Cassiolato e Lastres, 2000).

Em essência, a abordagem do sistema de inovação está relacionada, de acordo como o termo sugere, a "sistemas" — que remete à ideia de complexidade das conexões e diversidade de atores - e a "inovação" — que remete à ideia de dinamismo, mudanças tecnológicas. Por sua vez, o dinamismo está relacionado às mudanças tecnológicas, por meio das quais as empresas se adaptam e se modificam constantemente, buscando a sustentabilidade em longo prazo (Edquist, 1997; Carlsson et.al., 2002).

Contudo, o relacionamento entre os componentes sistêmicos não é linear: eles se interconectam de forma tão intricada que experts não foram capazes, até agora, de clarificar completamente todas as suas possíveis interações. Além disso, o processo de inovação nas empresas não é homogêneo, assumindo diversas formas e fazendo uso de diferentes fontes de recursos necessários para resolver seus problemas técnicos e implementar atividades de inovação. Ele também varia de acordo com as diversas características das próprias empresas, do estágio de desenvolvimento tecnológico já alcançado por um setor produtivo específico e mesmo com a capacidade das empresas em absorver novos desenvolvimentos (Rezende e Vedovello, 2006).

Desta forma, Cassiolato e Lastres (2000) enfatizam que a visão sistêmica da inovação envolve a discussão tanto do desempenho da firma isoladamente, quanto, sobretudo, da integração das firmas em complexas relações econômicas e sociais com o seu contexto.

Nesse contexto, deve-se considerar que uma das principais características das empresas dos países emergentes (latecomers) refere-se a suas deficiências de recursos ou de capacidades tecnológicas. Conforme Figueiredo (2009), as latecomers estão em geral deslocadas das fontes-chave de tecnologia como as universidades, laboratórios e centros de P\&D, ou seja, a infraestrutura tecnológica que as cerca tende a ser em geral precária. Contudo, essa situação deve ser relativizada, pois as possibilidades de interação, de mobilidade e conectividade contribuem para evitar o isolamento das latecomers, sobretudo quando participantes de cadeias produtivas e inseridas nos sistemas de inovação (Figueiredo, 2009).

Nesse sentido, as empresas que iniciam suas atividades numa condição de recursos escassos têm de buscar conhecimento de fora a fim de construir e acumular suas próprias capacidades. Para uma empresa obter e/ou desenvolver suas capacidades inovadoras, a alavancagem de recursos externos é um dos principais meios para executar as estratégias de catching-up e/ou de ultrapassagem (overtaking) da fronteira tecnológica. 


\subsection{A P\&D e os processos de aprendizagem}

Segundo o Manual de Oslo (2005), as atividades de inovação consistem em fases científicas, tecnológicas, organizacionais, financeiras e comerciais, compreendendo, ainda, o investimento em conhecimentos. A aplicação dessas fases conduz à implementação de inovações. Toda a P\&D é considerada atividade de inovação. No Manual de Oslo (2005), a P\&D é definida como uma categoria à parte que inclui tanto atividades importantes para as inovações de produto e de processo, como de marketing e organizacionais, juntamente com a pesquisa básica.

O manual Frascati (2002) define P\&D como trabalho criativo realizado de forma sistemática com a finalidade de aumentar o estoque de conhecimentos, incluindo os conhecimentos do homem, da cultura e da sociedade, e o uso desse estoque de conhecimentos para antever novas aplicações.

Tendo por base a discussão anterior, evidencia-se que nos sistemas de inovação dos países de industrialização tardia o governo tem o papel de promotor, regulador, executor e financiador do desenvolvimento científico, da pesquisa e da capacitação tecnológica. As instituições dos sistemas de inovação participam de programas governamentais de incentivo à cooperação, nos quais a responsabilidade pela implementação recai em geral sobre a universidade, laboratórios e institutos de P\&D (Moreira et al., 2007).

Bell (1993) desenvolveu uma discussão a partir de uma abordagem evolucionária acerca da introdução de atividades de P\&D e da infraestrutura tecnológica concomitante de economias desenvolvidas e daquelas de industrialização tardia. De acordo com Bell (1993), foi em economias desenvolvidas no início de 1900 que começou a surgir um processo formal de construção de atividades e competências de P\&D, por meio de uma evolução institucional e sua integração nas estruturas organizacionais dos setores produtivos como instalações específicas designadas a P\&D industrial dentro de grandes empresas e, ainda, o surgimento de institutos de $\mathrm{P} \& \mathrm{D}$ independentes.

Ainda segundo Bell (1993), somente no começo da década de 1950 países da América Latina, Ásia e, posteriormente, África construíram suas instalações de P\&D de uma forma bem diferente. Foram raras as capacidades de P\&D industrial, que evoluíram a partir de uma base prévia de atividades inovadoras menos especializadas e formalizadas. Elas foram criadas muitas vezes sem a coexistência de outras atividades que impulsionam o processo de mudança técnica - em especial, design e outros processos/atividades de engenharia de produção. Também não foram criadas a partir das capacidades construídas inicialmente dentro das empresas industriais. Em vez disso, eram geralmente estabelecidas em instituições centralizadas, que foram financiadas e operadas pelo governo (Bell, 1993).

Esta abordagem foi seguida precisamente porque se pensava que as empresas industriais ou eram muito pequenas ou de origem estrangeira, não tendo como objetivo estratégico precípuo o investimento em instalações de P\&D. Consultoria e assistência externa desempenharam um importante papel na criação de tais institutos e seus projetos surgiram muito mais como um reflexo de modelos do mundo industrializado do que como uma resposta orgânica ao ambiente imediato dos países em desenvolvimento por se. 
Bell (1993) complementa afirmando que não é surpresa que o problema da ligação entre os institutos de P\&D com o setor de produção tem sido uma prioridade da agenda política desde então. O mesmo autor menciona ainda que existe um gap crescente entre os centros de $\mathrm{P} \& \mathrm{D}$ e os setores produtivos.

Nesse sentido, Nelson (2007) releva a importância no século XXI do papel das universidades, laboratórios e institutos de P\&D participantes dos sistemas de inovação, a partir de transferência, difusão e aplicação de conhecimentos, visando o desenvolvimento econômico sustentável das regiões e países. Ainda segundo Nelson (2007), para que o treinamento e a pesquisa feita nas universidades e outras instituições públicas contribuam para o desenvolvimento econômico, é necessário adensar as ligações efetivas entre essas instituições, as organizações e os setores produtivos.

Nestes termos e tendo em vista a mudança tecnológica em empresas aglomeradas em redes e/ou em sistemas, Bell (1993) indica a necessidade da integração da P\&D com a estrutura produtiva das empresas, através do fortalecimento das ligações entre as estruturas institucionais existentes, sugerindo diferentes abordagens e estratégias que possibilitem esta integração e estimulem o desenvolvimento da capacidade de assimilação e aprendizagem tecnológica por parte das empresas.

Os institutos de P\&D surgem, portanto, no ambiente dos sistemas de inovação com o papel de serem o membro articulador entre os agentes devido à sua neutralidade em sanar as deficiências estruturais, sobretudo, em termos de desenvolvimento de mecanismos de aprendizagem e de competências tecnológicas (Bell, 1993).

O desenvolvimento de competências tecnológicas é nutrido por uma série de fatores, que são as fontes externas e internas para a construção dessas competências tecnológicas. Entre essas fontes estão os processos de aprendizagem intra e interorganizacionais, estando esses últimos formalizados através de diversas ligações, entre estas, aquelas entre as empresas e os institutos de pesquisa e desenvolvimento P\&D, participantes dos sistemas de inovação.

Ressalta-se para fins deste estudo a definição de aprendizagem segundo a perspectiva tecnológica que, conforme Bell (1984), é constituída por processos através dos quais as pessoas e, por meio delas, as organizações adquirem aptidões e conhecimentos técnicos (Bell, 1984). Já Figueiredo (2004) a conceitua como um processo que permite à empresa acumular capacidade tecnológica ao longo do tempo.

Os processos de aprendizagem são insumos que permitem à empresa acumular suas próprias competências tecnológicas, ampliando sua base interna de conhecimentos. Esses processos de aprendizagem tecnológica podem ocorrer através de mecanismos intraempresariais (alavancagem do conhecimento através dos mecanismos de aprendizagem externa e interna); e de mecanismos interempresariais, que ocorrem através do estabelecimento de vínculos tecnológicos entre empresas subsidiárias e entre as empresas e as demais organizações de apoio ao sistema de inovação, entre estas, os institutos de P\&D (Figueiredo, 2009).

Conforme Bell e Albu (1999), estas perspectivas anteriormente sintetizadas enfatizam a importância das "ligações internas" produzindo recursos geradores de mudança e das "ligações externas" facilitando os recursos geradores de conhecimentos, obtidos através de organizações especializadas como os institutos de P\&D. 
Ahuja (2000), em seu estudo sobre redes de empresas, também mostrou o efeito das ligações diretas e indiretas no desempenho de inovações. Uma ligação direta é o acesso à empresa com a qual se estabeleceu uma parceria, tal ligação ocorrendo sem a intermediação de terceiros. Por outro lado, ligações indiretas são os relacionamentos nos quais a empresa analisada tem algum tipo de acesso indireto a várias empresas ou outras organizações, por intermédio de uma empresa com a qual tem parceria direta. O autor demonstra que as ligações diretas entre empresas proporcionam compartilhamento de recursos e conhecimento, enquanto as ligações indiretas proporcionam apenas o compartilhamento de informações para a empresa focal (Ahuja, 2000).

As relações interorganizacionais se referem a qualquer tipo de contato entre duas ou mais organizações, variando da forma concorrencial e antagônica para aquelas de natureza cooperativa, tanto entre organizações similares quanto diferentes, envolvendo transações, fluxos e ligações de recursos relativamente duradouros (Oliver, 1990).

Nesse contexto, releva-se ainda a abordagem da inovação aberta (open innovation), na qual a empresa comercializa tanto as suas próprias ideias como as inovações de outras empresas e procura maneiras de levar suas ideias ao mercado por implantação de trajetos fora de seus negócios atuais. A fronteira entre a empresa e seu ambiente externo é porosa, permitindo a circulação de inovações com maior facilidade (Chesbrough, 2003).

No âmbito do debate sobre o dinamismo tecnológico dos sistemas de conhecimento essas perspectivas sugerem ainda as questões relativas às instituições que fazem o papel de "porteiros tecnológicos" (gatekeepers) ou "janelas tecnológicas" (technological windowing) provendo conhecimento novo aos sistemas de inovação (Schmitz, 2004; Rabellotti, 1995; Nadvi, 1996; Bell e Albu, 1999; Maggioni e Ricci, 2002).

Bell e Albu (1999) destacaram ainda a importância do entendimento dos papéis jogados pelas empresas, os institutos tecnológicos e ou outras organizações de apoio como "porteiros tecnológicos" em sistemas de conhecimento. E nesse sentido se sugere que a pesquisa futura em sistemas e redes industriais que tiver como objetivo entender a base de dinamismo tecnológico poderá combinar um foco na estrutura e relações das redes de empresas, com uma exploração dos recursos e processos de aprendizagem geradores de mudança que acontecem dentro/fora/entre as instituições e organizações participantes do sistema.

Para fins deste estudo pressupõe-se, portanto, no contexto do sistema de inovação, o papel de organizações de apoio, tipo os institutos de P\&D como gatekeeper ao acelerar a acumulação de capacidades tecnológicas das empresas, em termos de estratégias de catching-up (movimento de alcance) e overtaking (movimento de ultrapassagem).

Considera-se, ainda, a proposta de Bell e Albu (1999) quando sugerem que um passo inicial importante para entender "o dinamismo tecnológico" dos sistemas industriais seria desenvolver um "mapa dos fluxos e processos de conhecimento" (Bell e Albu, 1999).

Neste sentido, e considerando o objetivo precípuo desse estudo, ressalta-se o modelo desenvolvido por Vedovello e Figueiredo (2006), que avaliaram as ligações de aprendizagem entre as empresas e as organizações de apoio ao sistema de inovação, em particular os institutos de P\&D que venham a contribuir para o desenvolvimento do processo inovador em nível de empresas. 
O modelo baseia-se em uma taxonomia que considera a formalidade das ligações, ou seja, o comprometimento dos agentes envolvidos e o pagamento, ou não, de taxas e overheads em virtude dessas interações. Esses vínculos, segundo Vedovello e Figueiredo (2006), estão classificados em três tipos - informais, formais e os de recursos humanos - e três níveis — em termos de frequência, resultados obtidos e benefícios alcançados:

、 Ligações Informais: por meio desse conjunto de ligações, as empresas, em suas buscas por soluções técnicas ou em suas tentativas de implementar uma inovação, estabelecem contatos com um conjunto de informações e conhecimentos, expertise e equipamentos disponíveis nos institutos tecnológicos (e universidades). Por outro lado, institutos tecnológicos (e universidades) estabelecem contato com empresas e suas competências técnicas e científicas. O estabelecimento desses links não implica a existência de um contrato formal entre os parceiros, mesmo quando pequenos pagamentos estão envolvidos.

、 Ligações de Recursos Humanos: esse tipo de ligação relaciona-se com aprimoramento, treinamento e recrutamento e/ou alocação de força de trabalho qualificada. Esse grupo de links também amplia as possibilidades de promover-se educação técnica e continuada em áreas específicas de interesse das firmas. Pela perspectiva dos institutos tecnológicos (e universidades), pesquisadores individuais ou uma determinada unidade podem desejar fortalecer os laços com empresas com o intuito de: (1) aumentar as possibilidades de alocação de mão de obra qualificada; (2) estender sua base educacional e seu portfólio de pesquisa.

v Ligações Formais: por meio desse conjunto de links, as empresas, ao ficarem cientes dos recursos disponíveis nos institutos tecnológicos (e nas universidades) - conhecimento e informação, recursos humanos e equipamentos - , podem ter interesse em contratar o uso desses equipamentos, contratar projetos de pesquisa ou desenvolver pesquisas conjuntas, a fim de complementar seu esforço tecnológico interno. Pela perspectiva dos institutos tecnológicos (e universidades), eles podem desejar usar equipamentos industriais ou oferecer sua expertise científica a empresas e, assim, aumentar seu portfólio de pesquisa. Comumente, esses links pressupõem o estabelecimento de contratos formais entre os parceiros, com comprometimento de ambas as partes e realização de pagamentos previamente acordados.

\section{Contextualização e metodologia do estudo}

A metodologia de caráter descritivo e de natureza qualitativa teve como estratégia o estudo multicaso em três pequenas empresas participantes da cadeia produtiva da caprinocultura e inserida no sistema de inovação local do estado do Ceará.

Os instrumentos de coleta de dados no estudo de casos podem ser diversificados, o que confere flexibilidade à análise (Yin, 2001). Desta forma, em um primeiro momento foi utilizado o levantamento e a pesquisa documental em bases de dados institucionais, a fim de estabelecer um primeiro contato com a realidade estudada, assim como levantar dados históricos das empresas envolvidas. Conforme Gil (1991), a pesquisa documental é desenvolvida 
a partir de material já elaborado, mas que ainda não recebeu um tratamento analítico ou que ainda pode ser reelaborado de acordo com o objeto de pesquisa, sendo diversificadas as fontes de evidências. Esse autor aponta como vantagens da pesquisa documental o fato de os documentos serem uma fonte rica e estável de dados, possuírem baixos custos e dar possibilidade de fazer pesquisas sem haver o contato direto com os sujeitos da pesquisa.

A análise documental foi efetuada a partir de dados secundários tais como folders, livros, relatórios, matérias em websites, revistas e jornais gerados pelas empresas e pelo instituto de P\&D em estudo da Embrapa Caprinos e Ovinos, assim como em outras organizações participantes do sistema de inovação local, como: a Caprileice, Secretarias de Agricultura federal e estadual, órgãos de assistência técnica como a Empresa de Assistência Técnica e Extensão Rural do Ceará (Ematerce), a Food and Agriculture Organization of The United Nations (FAO), o Instituto Brasileiro de Geografia e Estatística (IBGE) e o Banco do Nordeste do Brasil (BNB).

No tocante às entrevistas, antes de sua execução foi elaborado um roteiro que refletiu os objetivos desse estudo. Foram realizadas entrevistas formais semiestruturadas com diretores de três pequenas empresas do setor da caprinocultura leiteira da região metropolitana de Fortaleza. O critério de seleção das empresas foi estabelecido pela acessibilidade e, sobretudo, por elas integrarem a Caprileice e participarem, através da Caprileice, do sistema de inovação local, mantendo, em consequência, ligações diretas e indiretas com o Instituto de P\&D da Embrapa Caprinos e Ovinos e com outras organizações como: universidades e centros de P\&D a estas associados; fornecedores e associações empresariais de classe.

Para complementar essas informações foram realizadas entrevistas abertas e informais com três pesquisadores da Embrapa Caprinos e Ovinos, dois técnicos da Ematerce, três diretores da Caprileice e com professores-pesquisadores do Programa de Pós-Graduação em Zootecnia da Universidade Federal do Ceará (UFC), da Rede Nordeste de Biotecnologia (Renorbio) ligados ao complexo laboratorial do Programa de Pós-Graduação em Ciências Veterinárias (PPGCV) da Faculdade de Veterinária da Universidade Estadual do Ceará (Uece) e, ainda, com um consultor do Ministério da Ciência e Tecnologia ligado à rede de P\&D do Sistema Brasileiro de Tecnologia (Sibratec).

As entrevistas formais com os empresários foram gravadas e foram feitas anotações abreviadas durante os contatos informais com os outros entrevistados. Triviños (1992) aponta a entrevista semiestruturada como um dos principais meios que possui o pesquisador qualitativo para coleta de informações, valorizando a presença do investigador, oferecendo todas as perspectivas para que o informante alcance a liberdade e a espontaneidade necessária, enriquecendo a investigação. Conforme esse mesmo autor, essa técnica parte de certos questionamentos básicos, apoiados em teorias e hipóteses as quais interessam à pesquisa e que em seguida oferecem amplo campo de interrogativas, fruto de novas hipóteses que vão surgindo à medida que se recebem as respostas do informante.

Na análise qualitativa das informações coletadas foi utilizada a técnica da análise temática que se insere no conjunto das técnicas da análise de conteúdo (Bardin, 2004), cujo objetivo é evidenciar os itens de significação a partir da descrição do corpus que foi construído, tendo por base as unidades de codificação recortadas do conteúdo das entrevistas e dos documentos, sendo essas orientadas pelos objetivos do estudo. Para isto, foram percorridas 
as diferentes fases de análise, entre elas: i) a pré-análise; ii) a exploração do material; e iii) o tratamento dos resultados tendo como base uma adaptação do modelo para a análise dos tipos de ligações de aprendizagem segundo Vedovello e Figueiredo (2006).

Os resultados estão apresentados em duas etapas, a primeira refere-se à descrição histórica relativa às empresas tendo como base o levantamento documental; a segunda etapa refere-se à análise propriamente dita, tendo como base os dados empíricos coletados nas entrevistas realizadas. Vergara (2006) acrescenta que nessa última etapa as suposições elaboradas poderão ou não ser confirmadas.

\section{Análise e resultados}

Conforme a história das empresas em estudo referenciado no levantamento documental, desde a segunda metade dos anos 1990 o programa da caprinocultura leiteira da região Nordeste do Brasil vem apresentando mudanças influenciadas pela implementação de diferentes políticas públicas. Nesse sentido, na cadeia produtiva da caprinocultura, sobretudo o segmento leiteiro (figura) foi estabelecido como prioridade para o desenvolvimento do sistema agropecuário do Nordeste brasileiro e por esse motivo passou a fazer parte de várias ações coordenadas, as quais estão promovendo o desenvolvimento do sistema de inovação local envolvendo as empresas participantes da cadeia produtiva da caprinocultura leiteira, foco deste estudo.

Figura

Fluxos de comercialização da cadeia produtiva do leite de cabra no Brasil

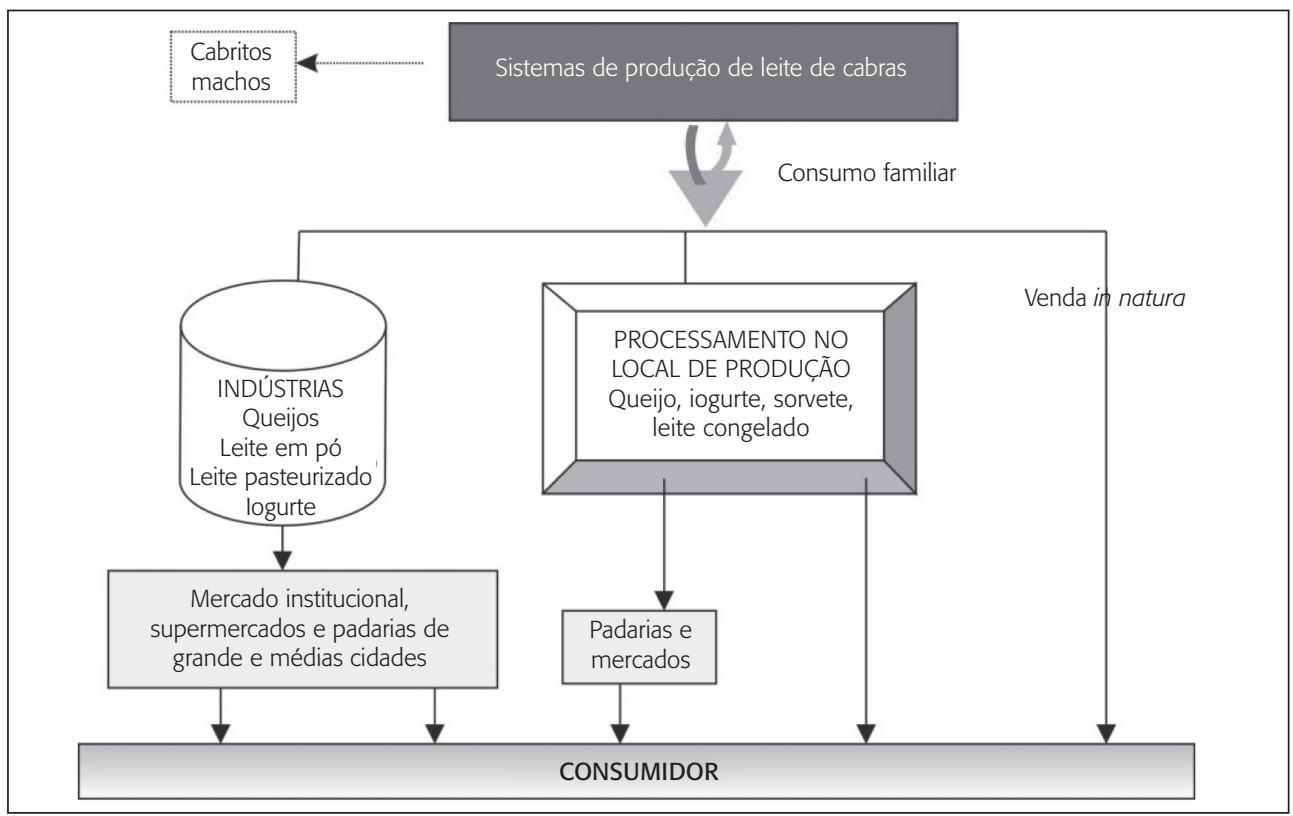

Fonte: Holanda Jr. e colaboradores (2008). 
Considerando especificamente o contexto da cadeia produtiva da caprinocultura leiteira, destaca-se o Programa de Incentivo à Produção e Consumo de Leite (PAA Leite), que se classifica como uma modalidade do Programa de Aquisição de Alimentos (PAA) desenvolvido com recursos dos Ministérios do Desenvolvimento Social e Combate à Fome (MDS) e do Desenvolvimento Agrário (MDA), como um instrumento de política pública do governo federal referendado na Lei no 10.696, de 2 de julho de 2003, que tem estimulado a produção de leite de cabra com a abertura de novos mercados institucionais.

O Programa de Aquisição de Alimentos (PAA) é uma das ações do programa governamental assim chamado "Fome Zero" e promove o acesso a alimentos às populações em situação de insegurança alimentar, promovendo a inclusão social e econômica no campo por meio do fortalecimento da agricultura familiar. O PAA também contribui para a formação de estoques estratégicos e para o abastecimento dos mercados institucionais de alimentos, compreendendo as compras governamentais de gêneros alimentícios para fins diversos e, ainda, permitindo aos agricultores familiares que estoquem seus produtos para serem comercializados a preços mais justos.

O PAA Leite atua em todos os estados da região Nordeste, sendo ainda beneficiado o Norte de Minas Gerais. Para desenvolver a modalidade, o Ministério do Desenvolvimento Social e Combate à Fome (MDS) firmou convênios com 10 governos estaduais, atendendo a 1,2 mil municípios. Diariamente, cerca de 700 famílias recebem o leite produzido por mais de 29 mil proprietários rurais. O produto é pasteurizado em laticínios cadastrados e, posteriormente, transportado para os pontos de distribuição às famílias (MDS, 2010).

Com base no PAA Leite e no âmbito local, o governo do estado do Ceará deu início em 2007 ao "Programa de Incentivo à Produção e Consumo de Leite de Cabra" no estado. O referido programa tem como objetivo apoiar, disponibilizar e difundir técnicas de criação de caprinocultura de leite, visando o melhoramento, viabilidade econômica e gestão da atividade. Nestes termos o PAA Leite objetiva:

i) Melhorar a produtividade e o índice zootécnico dos rebanhos;

ii) Promover a melhoria da sanidade;

iii) Difundir tecnologias de criação e gestão para os produtores familiares e pequenas empresas rurais.

A meta precípua do PAA Leite se baseia no combate à fome e à desnutrição de crianças de seis meses a seis anos de idade, gestantes e idosos, que estejam em situações de vulnerabilidade social e em estado de insegurança alimentar e nutricional. Para tanto realiza a distribuição gratuita do leite de cabra, apoiado pelo sistema produtivo local, garantindo a compra do leite dos produtores, dinamizando e fortalecendo, dessa forma, a cadeia produtiva local do setor com a abertura de novos mercados institucionais (SDA, 2010).

Nesta primeira fase da análise e tendo como base esse estudo histórico documental referente ao contexto institucional (envolvendo especificamente as políticas e programas governamentais do leite e os novos mercados institucionais emergentes) inerente ao sistema de inovação no qual a cadeia produtiva da caprinocultura leiteira está inserida, observou-se que 
as três empresas em estudo estavam ativando um conjunto de ações que têm como objetivos capacitar-se para o atendimento das exigências colocadas pelos editais de fomento das organizações governamentais no contexto dos programas governamentais do PAA Leite e nos quais as empresas entendiam participar.

Tendo como base essa discussão, evidenciaram-se da análise alguns temas relacionados aos diferentes posicionamentos estratégicos que as empresas em estudo estão utilizando para potencializar seu desempenho organizacional visando o alcance dos objetivos de negócio. Entre as estratégias de inovação utilizadas se relevaram as formas: i) imitativa, na qual a empresa reage à inovação se mantendo no mercado por meio de cópias com algumas modificações do projeto dos concorrentes; ii) a estratégia tradicional, que dispensa inovações tecnológicas ao acreditar que a empresa se insere em um setor que não demanda mudança; iii) e, por fim, a estratégia oportunista, que está sendo amplamente utilizada pelas empresas em estudo, tendo em vista a exploração de nichos de mercado a partir das possibilidades emersas com o PAA do Leite.

Objetivando incrementar seus processos e produtos e, consequentemente, explorar os novos mercados institucionais, as entrevistas e observações realizadas na segunda etapa da pesquisa levantaram um conjunto de dados e informações relativas aos tipos de ligações e articulações de aprendizagem entre as três empresas em estudo e as demais organizações do sistema de inovação local influente na cadeia produtiva da caprinocultura leiteira.

Nesse sentido, releva-se que as empresas em análise percebem a existência da organização da cadeia produtiva do segmento leiteiro, mas as ligações de aprendizagem, tanto diretas como indiretas, entre elas e as demais organizações do aparato institucional são de maneira geral ainda desarticulada. Contudo, as ações estratégicas em desenvolvimento pelas empresas evidenciam que estão sendo construídos diversos tipos de ligações de aprendizagem entre elas e algumas organizações do aparato institucional influentes na cadeia produtiva como: as duas universidades (UFC e Uece); o instituto de P\&D da Embrapa Caprinos e Ovinos; as empresas fornecedoras e a associação empresarial de classe, a Caprileice.

Em particular, em uma das empresas os resultados revelaram que ela está realizando alguns de seus processos de forma planejada, segundo estratégias imitativas e oportunistas, integrando os diferentes elos entre as empresas e algumas organizações no contexto da cadeia produtiva, objetivando o desenvolvimento de inovações e impulsionando o movimento no sentido de alcançar (catching-up) a fronteira inovadora da produção existente.

A organização e a análise dos resultados nesta segunda etapa da pesquisa foram baseadas em uma adaptação da taxonomia utilizada por Vedovello e Figueiredo (2006), que considera a formalidade das ligações, ou seja, o comprometimento dos agentes envolvidos no pagamento, ou não, de taxas e overheads em virtude dessas interações e, ainda, a caracterização das ligações informais e de recursos humanos, destacando-se em termos de frequência, resultados obtidos e benefícios alcançados. Esses resultados estão descritos a seguir e sumariados no quadro a seguir.

Em relação às ligações informais estabelecidas entre as empresas e o instituto de $\mathrm{P} \& \mathrm{D}$, evidenciou-se da análise que uma das empresas pesquisadas mantém contatos informais, mas frequentes com o instituto de P\&D da Embrapa Caprinos e Ovinos, tendo como objetivo o estabelecimento de projetos futuros. 
Contudo, emergiu da análise de conteúdos que diversas outras ligações informais, formais e de recursos humanos também estão sendo tecidas e construídas com outras instituições participantes do ambiente institucional do sistema de inovação, como: i) ligações diretas com pesquisadores da Uece e da UFC; ii) ligações indiretas e diretas com fornecedores de empresas locais e nacionais; iii) ligações indiretas e diretas com empresas pares e associadas à Caprileice; iv) assim como com empresas do mesmo setor de outras regiões da federação; e, por fim, v) ligações diretas com técnicos dos órgãos governamentais - Secretarias do Desenvolvimento Agrário - tanto do estado do Ceará como da cidade de Fortaleza e do âmbito federal.

Essas ligações evidenciadas na análise são periódicas e estão relacionadas, no caso das universidades (Uece e UFC), a estudos e demonstrações de aulas práticas do curso de veterinária e zootecnia. Os benefícios alcançados pelas empresas variam desde consultas a experimentações relacionadas aos cuidados nutricionais e de saúde das criações de caprinos.

No caso das ligações com o instituto de P\&D da Embrapa Caprinos, o objetivo foi aquele de articular e concretizar um convênio e projetos de pesquisa conjuntos em áreas tecnológicas específicas atendidas pela Embrapa Caprinos e Ovinos. A periodicidade desses contatos com a universidade é constante e semestral; com a Embrapa os contatos estão na fase inicial; além disso, estão sendo negociadas taxas e overheads para a concretização dessa interação, caracterizando, portanto, uma futura ligação formal.

Uma das empresas mantém ligações informais diretas com outras empresas do setor (em nível nacional - Mato Grosso do Sul), inclusive através de visitas técnicas a essas empresas. Foram detectados vínculos informais e indiretos, mantidos com frequência através de contatos on-line, entre sites e participações em discussões on-line de comunidades de práticas etc., entre esta empresa e outras empresas do mesmo setor e participantes de outras cadeias produtivas e sistemas de outras regiões do país.

Em relação às ligações formais, as empresas estudadas mantêm contatos diretos, sistemáticos e ativos com a Caprileice e com as Secretarias de Desenvolvimento Agro-Pecuário, concretizados, sobretudo, através da participação dos programas de assistência técnica, visando melhorias incrementais de produtividade e desempenho do sistema de produção para a integração das empresas nos programas governamentais dirigidos para o setor, visando explorar os mercados institucionais.

As três empresas em estudo também mantêm ligações formais, diretas e indiretas, de forma contínua com as empresas fornecedoras do setor, através do compartilhamento de informações, sobretudo, na área nutricional. Como as empresas participam dos programas governamentais do leite, são obrigadas a fazer levantamentos técnicos junto à Secretaria de Desenvolvimento Agro-Pecuário e com a Caprileice. A emergência desse novo mercado institucional, possibilitado pelo programa do leite (PAA Leite), está estimulando as empresas na busca de maiores interações formais, diretas e frequentes tendo como objetivo incrementar seus produtos e processos de gestão e, consequentemente, explorar maiores fatias desse mercado.

No que tange às ligações de recursos humanos, as empresas relevaram acessos diretos e indiretos à literatura especializada. Uma das empresas tem assinatura de periódicos da área, assim como consulta sites especializados, e todos os empresários proprietários participam de eventos técnicos, exposições e feiras - locais e nacionais - especializados na área, realizados 
pelas secretarias de governo estadual, municipal e federal, assim como por outras organizações influentes no ambiente do sistema de inovação. Eles também têm acesso à literatura produzida no contexto dessas instituições e das associações como a Caprileice.

Outra evidência de ligações formais de recursos humanos entre uma das empresas e o instituto de P\&D da Embrapa foi a participação do proprietário da empresa em cursos, seminários e conferências oferecidas por essa instituição, inclusive de assistência técnica no próprio local de trabalho, evidenciando ligações diretas de aprendizagem.

Ainda em relação às ligações diretas de recursos humanos, as empresas analisadas mantêm contatos com consultorias especializadas, como veterinários, pesquisadores da universidade e técnicos dos órgãos já citados. Por outro lado, os funcionários são incentivados a participar das reuniões promovidas pelas visitas técnicas dos órgãos governamentais e dos fornecedores. Os tipos de ligações de aprendizagem evidenciados estão sumariados no quadro.

\section{Quadro}

Tipos de ligações de aprendizagem entre as empresas, o instituto de P\&D e as organizações do sistema de inovação do qual a cadeia produtiva da caprinocultura leiteira do estado do Ceará participa

\begin{tabular}{|c|c|}
\hline Ligações Informais & $\begin{array}{l}\text { 1. Diretas com o instituto de P\&D da Embrapa Caprinos; } \\
\text { 2. Diretas com os professores e pesquisadores do curso de Veterinária da Uece; } \\
\text { 3. Diretas e indiretas com os fornecedores de outras empresas locais e nacionais participantes da cadeia } \\
\text { produtiva; } \\
\text { 4. Diretas com outras empresas parceiras associadas à Caprileice; } \\
\text { 5. Diretas e indiretas com outras empresas do mesmo setor localizadas em outras regiões do país, } \\
\text { inclusive mediante visitas técnicas a essas empresas; } \\
\text { 6. Diretas com técnicos dos órgãos governamentais tanto do estado como do município e do âmbito } \\
\text { federal. }\end{array}$ \\
\hline Ligações Formais & $\begin{array}{l}\text { 1. Diretas e sistemáticas com a Caprileice; } \\
\text { 2. Diretas e indiretas com as Secretarias de Agricultura do Estado do Ceará, do município e federal, } \\
\text { concretizadas, sobretudo, através da participação dos programas de assistência técnica e dos programas } \\
\text { governamentais de Aquisição de Alimentos PAA (PAA Leite); } \\
\text { 3. Diretas e indiretas com as empresas fornecedoras; } \\
\text { 4. Diretas com os órgãos governamentais e de assistência técnica como a Ematerce. }\end{array}$ \\
\hline Recursos Humanos & $\begin{array}{l}\text { 1. Diretas e indiretas para acessar a literatura especializada por meio de publicações, assinaturas de } \\
\text { periódicos e sites; } \\
\text { 2. Diretas a partir da participação em eventos técnicos, exposições e feiras especializadas na área, realizados } \\
\text { pela Secretaria de Agricultura Estadual e Municipal e outras organizações no âmbito nacional; } \\
\text { 3. Acessos diretos à literatura produzida no contexto dessas instituições e associações como a } \\
\text { Caprileice; } \\
\text { 4. Diretas a partir da participação de funcionários das empresas em cursos, seminários e conferências } \\
\text { oferecidas pelas organizações da área, inclusive de assistência técnica no próprio local de trabalho; } \\
\text { 5. Participação direta dos funcionários nos programas e reuniões promovidas pelas visitas técnicas dos } \\
\text { órgãos governamentais e dos fornecedores; } \\
\text { 6. Contatos frequentes diretos e indiretos com consultorias especializadas, como veterinários, } \\
\text { pesquisadores da universidade e técnicos dos órgãos já citados; } \\
\text { 7. Acontecem de forma mais ocasional e não sistematizada, de forma direta e indireta, com o instituto } \\
\text { de P\&D da Embrapa e de forma frequente com os órgãos de assistência técnica, com a associação } \\
\text { de classe (Caprileice) e com as universidades. }\end{array}$ \\
\hline
\end{tabular}

Fonte: Adaptado de Vedovello e Figueiredo (2006) segundo dados da pesquisa empírica. 
Da análise evidencia-se, portanto, que essas ligações de aprendizagem, sejam do tipo informais, formais, de recursos humanos, diretas e indiretas, estão possibilitando o desenvolvimento de capacidades inovadoras, acelerando em termos de catching-up as trajetórias tecnológicas por parte das empresas. Além disso, releva-se uma maior integração dos elos entre o setor produtivo e o instituto de P\&D da Embrapa Caprinos, assim como com as demais organizações participantes do ambiente institucional no qual se insere a cadeia produtiva da caprinocultura, entre elas: a Caprileice, a Ematerce, as secretarias de governo, as universidades, outras empresas fornecedoras e parceiras.

\section{Conclusões}

Considerando as diferentes estratégias utilizadas pelas empresas para potencializar seu desempenho por meio da inovação — se de liderança na fronteira tecnológica (overtaking) e/ou de seguimento tecnológico (catching-up) —, este estudo teve como objetivo identificar as ligações de aprendizagem entre um instituto de $\mathrm{P} \& \mathrm{D}$ e pequenas empresas participantes da cadeia produtiva da caprinocultura inserida no sistema de inovação local, tendo como base a seguinte questão: os institutos de $\mathrm{P} \& \mathrm{D}$ podem funcionar como porteiro tecnológico (gatekeepers) provendo conhecimento novo às empresas participantes dos sistemas de inovação?

Nas empresas estudadas observou-se que as mesmas mantêm estratégias de inovação do tipo imitativa e oportunista dirigidas para a concretização das ligações de aprendizagem com o instituto de P\&D da Embrapa Caprinos e Ovinos, assim como, conforme evidenciado da análise, com outras organizações do contexto institucional, entre elas: a associação de classe (Caprileice), o órgão governamental de assistência técnica (Ematerce), as Secretarias de governo (estadual, municipal e federal), as universidades, as empresas fornecedoras e outras empresas parceiras de outros estados do país.

Contudo, observou-se que apesar de muitas dessas ligações serem ainda informais e/ou indiretas, como com o instituto de P\&D da Embrapa, evidências mostraram que elas estão incidindo na ampliação da base de conhecimento das empresas em estudo, sobretudo por meio das ligações diretas, formais e de recursos humanos concretizadas com as demais instituições participantes do sistema de inovação local.

Neste sentido, releva-se como um dos resultados desse estudo que além dos institutos de $P \& D$, outras instituições como as universidades, empresas fornecedoras, associações de classe como a Caprileice, outras empresas parceiras e secretarias de estado e órgãos governamentais de assistência técnica como Ematerce também podem funcionar como porteiros tecnológicos (gatekeepers) provendo conhecimento novo às pequenas empresas participantes dos sistemas de inovação. Nesse sentido, considera-se que estas estratégias — tanto as imitativas como oportunistas - estão alavancando os processos de aprendizagem das empresas em estudo e estimulando o desenvolvimento de inovações no sentido de alcançar (catching-up) a fronteira inovadora da produção, possibilitando a exploração de fatias dos mercados institu- 
cionais emergentes através dos programas governamentais direcionados à cadeia produtiva da caprinocultura do Nordeste.

Relevou-se da análise que as ligações informais diretas e indiretas são mais frequentes com o instituto de P\&D da Embrapa, bem como com as universidades e com as demais empresas parceiras de outras regiões. As ligações formais diretas e indiretas acontecem com frequência com as empresas fornecedoras, com as secretarias de governo, com os órgãos governamentais e de assistência técnica como a Ematerce e com as associações de classe como a Caprileice. As ligações de recursos humanos acontecem de forma indireta, ocasional e não sistematizada com o instituto de P\&D da Embrapa e de forma direta e frequente com os órgãos de assistência técnica (Ematerce), com a associação de classe (Caprileice) e com as universidades (UFC e Uece).

Por outro lado e para que ocorra a materialização e intensificação das ligações de aprendizagem formais, relevou-se da análise que se faz necessário o provimento de condições específicas, tais como: estágio de desenvolvimento tecnológico visando o aprimoramento da capacidade das empresas em integrar novos conhecimentos com a base de conhecimento já existente; socialização do conhecimento dos recursos humanos envolvidos (tanto por parte das empresas, como pela infraestrutura tecnológica) e capacidade financeira para apoiar atividades de P\&D mais robustas. Nas empresas em pauta, verificou-se ainda que o setor atua de forma acanhada com relação à ampliação, conversão e disseminação dentro da empresa dos processos de aprendizagem interorganizacionais obtidos das fontes externas.

A análise também sugere que a infraestrutura tecnológica deveria ser considerada como uma questão central no desenho e na implementação de políticas públicas governamentais para o desenvolvimento de competências industriais, principalmente no âmbito de economias emergentes. A relação empresas/institutos de P\&D, por ter flexibilidade limitada e ainda a carga da burocracia inerente, termina por ver dificultada sua concretização. Nestes termos, a intervenção governamental se torna imprescindível para o desenvolvimento dessas interações e sua integração, diminuindo o gap existente entre essas organizações e o setor produtivo ao promover o desenvolvimento inovador.

Este estudo contribuiu para o conhecimento na área ao clarificar o entendimento dos processos de aprendizagem interorganizacionais, sobretudo aqueles baseados nas ligações formais, informais e de recursos humanos, diretas e indiretas entre um instituto de P\&D, as demais organizações de apoio e pequenas empresas participantes da cadeia produtiva da caprinocultura leiteira, inserida no sistema de inovação local do estado do Ceará.

Contrariando certas generalizações negativas e pessimistas, as evidências deste estudo mostraram um campo promissor para estudos e aprofundamentos posteriores. Conforme evidências articuladas na análise, ressaltam-se a necessidade de melhor explorar a influência de fatores internos (como a liderança corporativa) para a iniciativa das empresas em termos de aprendizagem e, em consequência, de desenvolvimento de capacidades tecnológicas. Desta forma, sugere-se que esses focos sejam seguidos em trabalhos futuros, inclusive, através de estudos comparativos entre empresas associadas à Caprileice e participantes do sistema de inovação local, abrangendo também outros estados e regiões. 
O agronegócio é de importância estratégica para a economia brasileira. Com a globalização de mercados, o sucesso de uma empresa, principalmente no agronegócio, depende cada vez mais da inter-relação entre as várias instituições de apoio como os institutos de P\&D, fornecedores, produtores de matéria-prima, distribuidores e a infraestrutura tecnológica, articulando os elos das e entre as cadeias produtivas, fortalecendo assim os sistemas de inovação agropecuários.

\section{Referências}

AHUJA, G. Collaboration networks, structural holes, and innovation: a longitudinal study. Administrative Science Quarterly, v. 45, p. 425-455, 2000.

AMSDEN, A.H. Asia's next giant: South Korea and late industrialization. New York: Oxford University Press, 1989.

BARDIN, L. Análise do conteúdo. Lisboa: Edições 70, 2004.

BELL, M. Integrating R\&D with industrial production \& technical linkages \& changing structures. Economic and Social Commission for Western Asia. Unido/HCST/Ifstad. 1993. Memo. 30 p.

BELL, M. Learning and the accumulation of industrial technological capacity in developing countries. In: KING, K.; FRANSMAN, M. (Ed.). Technological capability in the Third World. London: Macmillan, 1984.

BELL, M.; ALBU, M. Knowledge systems and technological dynamis in industrial cluster in developing countries. World Development, v. 27, n. 9, p. 1715-1734, 1999.

BELL, M.; PAVITT, K. The development of technological capabilities. In: UI HAQUE, I. et al. Trade, technology and international competitiveness. Washington: The World Bank, 1995. p. 69-101.

BEN, F. Acumulação de competências tecnológicas e suas implicações para a performance corporativa: um estudo comparativo entre duas empresas da indústria moveleira em Bento Gonçalves — RS. Dissertação (mestrado) - Escola Brasileira de Administração Pública e de Empresas, Fundação Getulio Vargas, Rio de Janeiro, 2001.

BESSANT, J. Enabling continuous and discontinuous innovation: learning from the private sector. Public Money and Management, v. 25, p. 35-43, 2005.

CARLSSON, B. et al. Innovation systems: analytical and methodological issues. Research Policy, v. 31, p. 233-245, 2002.

CASSIOLATO, J.E.; LASTRES, H.M.M. (Org.). Local, national and regional systems of innovation in the Mercosur. Industry and Innovation, v. 7, n. 1, 2000.

CHESBROUGH, H. Open innovation: the new imperative for creating and proofing from technology. Boston: Havard Business Scholl Press, 2003. 
COOPER, R.G. Perspective: The Stage-Gates Idea-to-Launch Process - Update, What's New, and NexGen Systems. Journal of Production and Innovation Management, v. 25, p. 213-232, 2008.

CUNHA, G.E. da; BIGNETTI, L.P. Estratégias de inovação em empresas de desenvolvimento de software Gramado RS. In: SIMPÓSIO DE GESTÃO DA INOVAÇÃO TECNOLÓGICA ANPAD, XXIV, 2006. Anais... Gramado, 2006. CD-ROM.

DANTAS, E.; BELL, M. The development of firm-centered knowledge networks in emerging economies: the case of Petrobras in the offshore oil innovation system in Brazil. In: DRUID summer conference. Copenhagen, 2006.

EDQUIST, C. Systems of innovation approaches - their emergence and characteristics. In: EDQUIST, C. (Ed.). Systems of innovation: technologies, institutions and organizations. Pinter: London, 1997. p. 1-35.

FRASCATI manual: standard method proposed for surveys of experimental research and development. Paris: OECD, 2002.

FIGUEIREDO, P.N. Gestão da inovação: conceitos, métricas e experiências de empresas no Brasil. Rio de Janeiro: LTC, 2009.

FIGUEIREDO, P.N. Aprendizagem tecnológica e performance competitiva. Rio de Janeiro: Fundação Getulio Vargas, 2003.

FIGUEIREDO, P.N. Aprendizagem tecnológica e inovação industrial em economias emergentes: uma breve contribuição para o desenho e implementação de estudos empíricos e estratégias no Brasil. Revista Brasileira de Inovação, v. 3, n. 2, p. 323-361, jul./dez. 2004.

FREEMAN, C. Technological infrastructure and international competitiveness. Draft paper submitted to the OECD Ad Hoc Group on \Science, Technology and Competitiveness. 1982.

FREEMAN, C. Technology policy and economic performance: lessons from Japan. London: Pinter Publishers, 1987.

GREGERSEN, B.; JOHNSON, B. Learning economies, innovation systems and European integration. Regional Studies Association, v. 31.5, p. 479-490, 1996.

GIL, A.C. Como elaborar projetos de pesquisa. 3. ed. São Paulo: Atlas, 1991.

HOBDAY, M. Innovation in East Asia: the challenge to Japan. Aldershot: Edward Elgar, 1995.

HOBDAY, M. OEM and TNC-led growth in electronics: comparing East and South Asian innovation systems. In: DUTRÉNIT, G.; GARRIDO, C.; VALENTI, G. (Ed.). Sistema Nacional de Innovación: temas para el debate en México. Mexico: UAM, 2000. p. 343-360.

HOLANDA JÚNIOR, E.V. et al. Custo de produção de leite de cabra no Nordeste. In: SEMANA DE CAPRINOCULTURA E OVINOCULTURA/ZOOTEC2008, VII, João Pessoa. Anais... João Pessoa: ABZ, 2008.

LASTRES, H.M.M.; CASSIOLATO, J.E. Sistemas de inovação e desenvolvimento das implicações de política. Revista São Paulo em Perspectiva, v. 19, n. 1, p. 34-45, 2005. 
LEE, K.; LIM, C. Technological regimes, catching-up and leapfrogging: findings from the Korean industries. Research Policy, v. 30, n. 3, p. 459-483, 2001.

LUNDVALL, B. Innovation as an interactive process: from user-producer interaction to the national system innovation. In: DOSI, G. Technical change and economic theory. London /New York: Pinter Publishers, 1982. p. 309-398.

LUNDVALL, B. National innovation systems - analytical concept and development tool. Industry and Innovation, v. 14, n. 1, p. 95-119, 2007.

MAGGIONI, M.A.; RICCI, M. Forme alternative di collective learning: um approccio sistemico-popolazionista ed alcune simulazioni. In: CAMAGNI, R.; CAPELLO, R. (A cura de). Apprendimento colletivo e competitività territoriale. Milano: Franco Angeli, 2002.

MANUAL DE OSLO. OECD-EC. Diretrizes para coleta e interpretação de dados sobre inovação (1997). Tradução de Flávia Gouveia. 3. ed. Rio de Janeiro: Arti/Finep, 2005. p. 149-151.

MINAYO, M.C. de S. et al. Pesquisa social: teoria, método e criatividade. 23. ed. Petrópolis: Vozes, 2004.

MINISTÉRIO DO DESENVOLVIMENTO SOCIAL E COMBATE À FOME (MDS). Programa de aquisição de alimentos. Disponível em: <www.mds.gov.br/falemds/perguntas-frequentes/seguranca-alimentar-e-nutricional/programa-de-aquisicao-de-alimentos-paa/gestor/programa-de-aquisicao-de-alimentos-paa >. Acesso em: 10 set. 2010.

MOREIRA, N.V.A. et al. A inovação tecnológica no Brasil: avanços no marco regulatório e a gestão dos fundos setoriais. Revista de Gestão USP, São Paulo, v. 14, n. esp., p. 31-44, 2007.

NADVI, K.M. Small firm industrial districts in Pakistan. IDS D.Phil (thesis) - University of Sussex, Brighton, 1996.

NELSON, R.R. National innovation systems: a comparative analysis. New York/Oxford: Oxford University Press, 1993.

NELSON, R. The changing institutional requirements for technological and economic catch up. International Journal of Technological Learning, Innovation and Development, v. 1, n. 1, p. 4-12, 2007.

NELSON, R.R.; ROSENBERG, N. Technical innovation and national systems. In: NELSON, R. (Ed.). National innovation systems: a comparative analysis. New York: Oxford University Press, 1993.

OLIVER, C. Determinants of interorganizational relationships: integration and future directions. Academy of Management Review, v. 15, n. 2, p. 241-265, 1990.

PORTER, M.E. Industrial organization and the evolution of concepts for strategic planning: the new learning. Managerial and Decision Economics, v. 4, n. 3, p. 172-180, 1983.

PORTER, M.E. The competitive advantage of nations. New York: The Free Press, 1990.

RABELLOTTI, R. External economies and cooperation in industrial districts: a comparison of Italy and Mexico, IDS D.Phil T (thesis) — University of Sussex, Brighton, 1995.

REZENDE, S.M.; VEDOVELLO, C. Agências de financiamento como instrumento de política pública em ciência, tecnologia e inovação: o caso da Financiadora de Estudos e Projetos (Finep). Parcerias Estratégicas, n. 23, 2006. 
SCHMITZ, H. Local enterprises in the global economy: issues of governance and upgrading. Edward Elgar Publishing, 2004.

SCHUMPETER, J. Teoria do desenvolvimento econômico. São Paulo: Abril Cultural, 1982.

SECRETARIA DO DESENVOLVIMENTO AGRÁRIO (SDA). Ceará. Edital de credenciamento para o incentivo a produção e consumo de leite de cabra no Estado do Ceará. Fortaleza, 2010.

TACLA, C. Acumulação de competência tecnológica e os processos subjacentes de aprendizagem na indústria de bens de capital: o caso da Kvaerner Pulping no Brasil. Dissertação (mestrado) - Escola Brasileira de Administração Pública e de Empresas, Fundação Getulio Vargas, Rio de Janeiro, 2002.

TRIVIÑOS, A.N.S. Introdução à pesquisa em ciências sociais: a pesquisa qualitativa em educação. São Paulo: Atlas, 1992.

VEDOVELLO, C. Perspectivas e limites da interação entre universidades e MPMEs de base tecnológica localizadas em incubadoras de empresas. Revista do BNDES, v. 8, p. 281-316, 2001.

VEDOVELLO, C. Science parks and the university-industry links: a case study of the Surrey Research Park. PhD (thesis) — SPRU, University of Sussex, Brighton, 1995.

VEDOVELLO, C.; FIGUEIREDO, P.N. Capacidade tecnológica industrial e sistema de inovação. Rio de Janeiro: Editora FGV, 2006.

VERGARA, C.S. Métodos de pesquisa em administração. São Paulo: Atlas, 2006.

YIN, R.K. Estudo de caso: planejamento e métodos. 2. ed. Porto Alegre: Bookman, 2001.

Ana Sílvia Rocha Ipiranga é professora adjunta do curso de mestrado acadêmico em administração da Universidade Estadual do Ceará (Uece). E-mail: ana.silvia@pq.cnpq.br.

Waleska Vasconcelos Queiroz é mestre pelo curso de mestrado acadêmico em administração da Uece. E-mail: waleskavq@hotmail.com.

Gleildes dos Santos Lima Frota é mestre pelo curso de mestrado acadêmico em administração da Uece. E-mail: gleildeslima@hotmail.com.

Samuel Façanha Câmara é professor adjunto do mestrado em administração da Uece. E-mail: sfcamara@ ig.com.br.

Priscilla Corrêa da Hora Almeida é mestre em administração pela Uece. E-mail: prishora@yahoo.com.br. 